\title{
Influence of Alkali Treatment and Dune Sand Content on the Properties of Date Palm Fiber Reinforced Unsaturated Polyester Hybrid Composites
}

\author{
Yazid Meftah $^{1,2^{*}}$, Masoud Tayefi ${ }^{3}$, Fatma Fellouh $^{4}$, Houria Chouieur $^{4}$, Samira Maou $^{2,4}$, Ahmed Meghezzi $^{2}$ \\ ${ }^{1}$ Ecole Normale Supérieure de Boussaada, Boussaada 28201, Algeria \\ ${ }^{2}$ Laboratoire de Chimie Appliquée, Université Mohamed-Kheider de Biskra, Biskra 07000, Algeria \\ ${ }^{3}$ Iran Polymer and Petrochemical Institute, Tehran 1497713115, Iran \\ 4 Département de Chimie, Université Hassiba Ben Bouali de Chlef, Chlef 02180, Algeria
}

Corresponding Author Email: yazid.meftah@univ-biskra.dz

https://doi.org/10.18280/rcma.303-406

Received: 8 February 2020

Accepted: 17 April 2020

\section{Keywords:}

date palm fiber, dune sand, hybrid composites, physical properties, unsaturated polyester

\begin{abstract}
The effects of alkali treatment and dune sand (DS) addition on the mechanical, morphological, thermal and water absorption behavior of date palm fiber (DPF) reinforced unsaturated polyester (UP) composites were investigated. The composites were synthesized by hand lay-up method with 10,20 , and $30 \mathrm{wt} \%$ of both treated and untreated date palm fiber (TDPF/DPF). Furthermore, composites having 10, 20 and 30 $\mathrm{wt} \%$ of untreated date palm fiber and dune sand (both of them were in equal wt $\%$ ) were also fabricated. Alkali treatment improved the tensile strength, tensile modulus, flexural strength and flexural modulus of the resulting composites. Scanning electron microscopy (SEM) revealed the better interfacial interaction of treated date palm fibers/UP composites. Thermogravimetric analysis (TGA) showed that thermal stability, and degradation temperature of treated DPF composites were best over the untreated DPF composites. Water absorption test indicated the decreasing of hydrophilic character of the filler after treatment with sodium hydroxide $(\mathrm{NaOH})$. Overall analysis represented that satisfactorily improved physical properties of UP for various engineered and hi-tech applications were obtained with $10 \mathrm{wt} \%$ fillers loading (5 wt $\%$ date palm fiber and $5 \mathrm{wt} \%$ dune sand particles).
\end{abstract}

\section{INTRODUCTION}

Unsaturated polyester (UP) is one of the most used thermosetting polymers, because it can be easily handled, as well as it has good mechanical properties and relatively low cost. Polyester is widely used in industry, for example in automotive, aircraft, aeronautic, electrical, or building materials industry [1-3].

The valorization of date palm fiber (DPF) $[4,5]$ and dune sand (DS) $[6,7]$ in material engineering is an important economic activity in northern Africa.

The addition of natural inorganic fillers, such as sand to UP, with different proportions is possible and it has a substantial potential for various engineering applications [7, 8].

Ahmad et al. [9] have studied the influence of silica sand nanoparticles on the mechanical and thermal properties of composites based on epoxy. They have reported that the maximum optimal Young's modulus of the composites was achieved by adding 15 wt.\% nanoparticles of silica sand. However, they noticed a decrease in tensile strength. In addition, differential scanning calorimetry (DSC) analysis revealed that the addition of fillers caused a reduction in degree of crystallinity of the nanocomposites.

Ahmad et al. $[10,11]$ also conducted a research on the epoxy and polyester-based composites to study the influence of nanoparticles of Tronoh silica sand as well as glass fiber on the mechanical and thermal properties of the systems. The results showed that addition of nanoparticles improved the mechanical and thermal properties of the developed composites. In addition, the bonding of silica sand nanoparticles with the glass fibers and a homogeneous dispersion of the reinforcement in the matrix were clearly observed in SEM image.

An improvement in the mechanical, electrical and thermal properties of UP was also achieved through its mixing with natural fibers providing higher performance in comparison with inorganic fillers [12].

However, the interfacial adhesion of fiber needs to be improved by treating prior it can be used as a filler, which is due to a strong affinity of natural fibers toward moisture which makes them hydrophilic and polar in nature [13, 14]. Consequently, employing alkali treatment process can improve the surface interaction of natural fibers with polymers that most are nonpolar, hydrophobic materials. This causes an improved interlocking of fibers with their polymer matrix [15, 16]. However, $6 \mathrm{wt} \% \mathrm{NaOH}$ was found to enhance mechanical properties more than $9 \mathrm{wt} \% \mathrm{NaOH}$ [17].

Recently, much effort has been devoted to prepare composites reinforced with hybrid fillers [18-20]. However, there is a lack of using Dune Sand and palm fiber to unite the advantages of these two diverse filler types such as: good mechanical properties and thermal stability (Dune Sand) as well as low weight, eco-friendly nature and high specific strength, low energy consumption (date palm fiber), 
respectively, in a hybrid composites material, based on unsaturated polyester.

To the best of our knowledge, there are no studies regarding hybrid natural filler composites in conjunction with unsaturated polyester.

Our work aims to use date palm fiber and dune sand in the production of eco-friendly hybrid composites. In this article, the effects of alkali treatment and dune sand addition on the mechanical, morphological, thermal and water absorption behaviors of DPF reinforced UP composites were investigated. Moreover, we used cheap waste materials abundantly present in Saharan countries, in particular, the aforementioned DPF and DS as reinforcements of the new hybrid composites used in various engineered and hi-tech applications with optimum thermal and mechanical behaviors.

\section{MATERIALS AND METHODS}

\subsection{Materials}

The orthophthalic unsaturated polyester resin and methylethyl-ketone peroxide (MEKP) were supplied from LORN Chemicals Company, Algeria.

Natural sand was collected from dunes of Ouargla, Algeria. Physical characteristics of Dune sand have been tabulated in Table 1.

Table 1. Physical characteristics of dune sand [6]

\begin{tabular}{cc}
\hline $\begin{array}{c}\text { Absolute } \\
\text { specific gravity }\end{array}$ & 2.62 \\
\hline $\begin{array}{c}\text { Apparent } \\
\text { specific gravity }\end{array}$ & 1.46 \\
\hline Sand equivalent & 82.20 \\
\hline $\begin{array}{c}\text { Fineness } \\
\text { modulus }\end{array}$ & 0.96 \\
\hline Porosity & 0.16 \\
\hline \% Silica & 99 \\
\hline diameter $(\mathbf{m m})$ & $0.063-0.25$ \\
\hline
\end{tabular}

Natural sand was washed in water and dried at $100^{\circ} \mathrm{C}$ for 24 hours.

DPFs were obtained from the date farm's agricultural waste in Biskra, Algeria. DPF was washed, ground and sieved. The sieved fiber was dried in a laboratory oven at $50^{\circ} \mathrm{C}$ to a final moisture content of 3-4\% and was stored in polyethylene bags for further compounding. The chemical composition of date palm fibers from leaf is shown in Table 2.

Table 2. Chemical composition of leaf date palm fibers [21]

\begin{tabular}{cc}
\hline cellulose & 40.21 \\
\hline hemicelluloses & 12.8 \\
\hline Lignin & 32.2 \\
\hline ash & 10.54 \\
\hline Extractive & 4.25 \\
\hline
\end{tabular}

\subsection{Surface modification of date palm fibers with $\mathrm{NaOH}$}

The procedure adopted for the fiber treatment with hydroxide solution was as follows:

The DPFs were immersed into $\mathrm{NaOH}$ solutions at concentration $(6 \%)$ for 24 hours at room temperature, and then they were washed several times with distilled water followed by neutralization with acetic acid $(2 \%)$ until the $\mathrm{PH}=7$. After that, the modified fibers were recovered by filtration and dried at $80^{\circ} \mathrm{C}$ for $24 \mathrm{~h}$.

\subsection{Fabrication of composites}

The treated and untreated date palm fibers and dune sand were reinforced into unsaturated polyester resin to make the composites. The composites were fabricated using the hand lay-up technique.

First, the DPF, DS and UP resin were mixed in different weight ratios, then the mixtures were mixed with 2 wt.\% methyl ethyl ketone peroxide. Immediately, the mixtures were poured into a steel mold having dimensions of $200 \mathrm{~mm} \times 200$ $\mathrm{mm} \times 2 \mathrm{~mm}$. A wax was used to facilitate easy removal of the composites from the mold after curing. The steps of fabrication process of filler (dune sand and/or date palm fiber) reinforced UP composites are depicted in Figure 1.
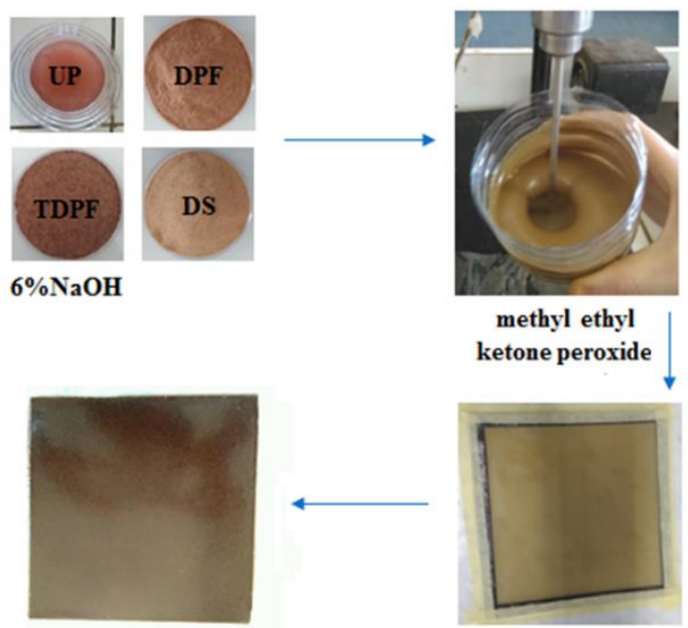

Figure 1. Process flow chart for the fabrication of filler (dune sand and/or date palm fiber) reinforced UP composites

\subsection{Characterization}

\subsubsection{Mechanical characteristics}

Tensile and Flexural tests were carried out according to ASTM D 303 and D 790 standards, respectively, using a mechanical testing machine (HL-590).

\subsubsection{Morphological analysis}

The morphology of the composites was studied using a (VEGA 3 TESCAN) scanning electron microscope (SEM).

\subsubsection{Thermal properties}

The thermograms of the polymeric matrix and the composites were recorded by using SDT Q600 (TGA/DSC simultaneous thermogravimetric analyzer and differential scanning calorimeter) from TA Instruments under N2 atmosphere from room temperature up to $600^{\circ} \mathrm{C}$ using a heating rate of $10^{\circ} \mathrm{C} / \mathrm{min}$.

\subsubsection{Water absorption test}

The percentage of water absorption in the composites measured every 24 hours for a total of 35 days [22] and the water absorption was determined by difference of weight between the samples immersed in water and the dry samples using the subsequent equation: 


$$
M_{t}=\left(\frac{W_{t}-W_{0}}{W_{0}}\right) \times 100
$$

where, $M_{t}$ is moisture uptake percentage, $W_{0}$ and $W_{t}$ are the mass of the dry weight of the sample and the weight at any specific time $t$, respectively.

\section{RESULTS AND DISCUSSION}

\subsection{Mechanical properties}

\subsubsection{Tensile properties of the composites}

Tensile strength and tensile modulus of polyester based composites are shown in Figure 2. The sample C1 (reinforced with $10 \mathrm{wt} \%$ of date palm fiber) showed higher tensile strength and tensile modulus in comparison with the virgin polyester, due to the good dispersion of the DPF and the high interfacial bonding between matrix and DPF. These results are in agreement with Rahman et al. who reported that Tensile strength and tensile modulus of wood flour (WF) / UP composites increased with increase in filler content up to $15 \%$ [23]. The figure indicates that both the tensile strength and modulus increased with alkali treatment. For example, the maximum tensile strength $(32.12 \pm 1.8 \mathrm{MPa})$ and tensile modulus $(689 \pm 19.5 \mathrm{MPa})$ were obtained for $\mathrm{C} 4$ (reinforced with $10 \mathrm{wt} \%$ of treated date palm fiber). The obtained experimental results indicate that alkali treatment of date palm fibers improved tensile strength of composites in accordance with previous studies [24, 25].

Further increasing of the reinforcement's percentage decreased tensile strength and modulus. All the composites were brittle. This may be due to agglomeration of the sand particles and reduction in the interfacial bonding between matrix and sand [26].

The optimum tensile strength $(38.9 \pm 2.1 \mathrm{MPa})$ and tensile modulus $(719 \pm 23 \mathrm{MPa})$ were obtained with $10 \mathrm{wt} \%$ fillers content ( $5 \mathrm{wt} \%$ date palm fiber and $5 \mathrm{wt} \%$ dune sand particles), C7. At the initial stage of the tensile test, a delay in fracture process was also observed, when fibers separated from the polymer matrix. Following this, small cavities were generated in samples filled by sand particles, which this process is so called pulling and fracturing mechanism of the fibers as discussed by Ahmad et al. [11]. In addition, this improvement can be attributed to the good dispersion of date palm fiber and dune sand particles within the matrix, this result is in line with those showed in presence of $(5 \mathrm{wt} \%)$ Luffa fiber, $(5 \mathrm{wt} \%)$ $\mathrm{CaCO}_{3}$ and Polyester-based matrix [27].

\subsubsection{Flexural properties of the composites}

Flexural is among the most important mechanical properties of thermosets, which is its ability to resist deformation under load [28]. Figure 3 shows that alkali treatment improves both flexural strength and modulus of date palm fiber/UP composites. The flexural strength of untreated date palm composites increased from $53.66 \pm 3.3$ to $55.5 \pm 4.6 \mathrm{MPa}$, from $44 \pm 4.8$ to $48 \pm 4.4 \mathrm{MPa}$ and from $40 \pm 4.8$ to $43.33 \pm 4.5 \mathrm{MPa}$ when filled by adding $10 \%, 20 \%$, and $30 \%$ treated date palm fiber, respectively $[29,30]$.

Furthermore, the flexural strength and modulus of $10 \mathrm{wt} \%$ fillers content $(5 \mathrm{wt} \%$ date palm fiber and $5 \mathrm{wt} \%$ dune sand particles) composites, C7, are $62 \pm 6.27$ and $2834 \pm 370.80$ $\mathrm{MPa}$, respectively, which are the optimum values. The possible reason for these results is the improved interfacial adhesion of the fibers and matrix, which is resulted from a better distribution of sand in matrix. The micrographs from SEM also supported that sand have well distributed to the matrix.

Ahmad et al. [10] also reported that the delay of fracture in impact test is due to pulling and breaking mechanism of fibers from polymer matrix.

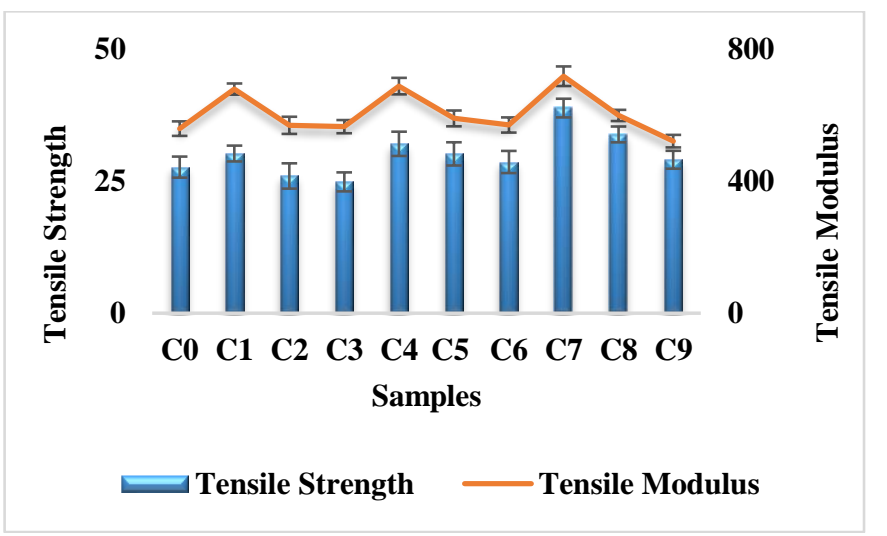

Figure 2. Tensile strength and modulus of the composites

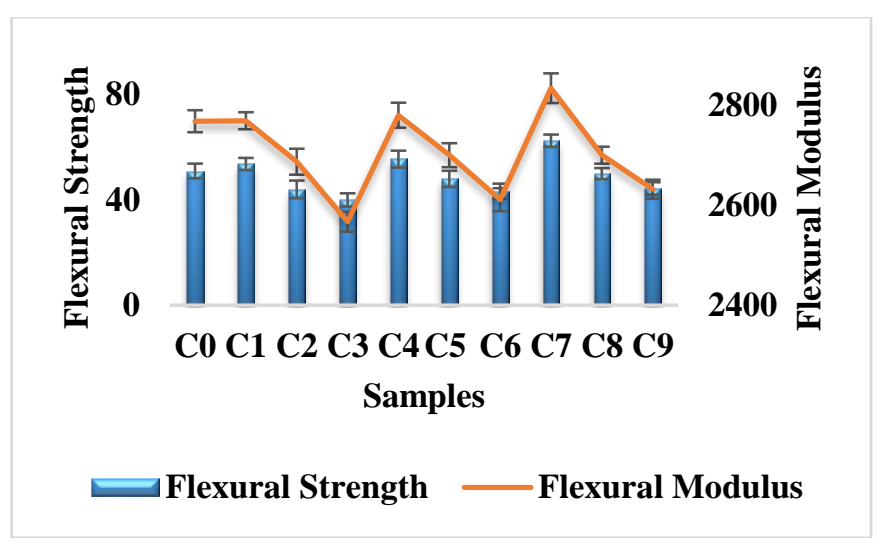

Figure 3. Flexural strength and modulus of the composites

\subsection{Morphological properties}

Figure 4 a-d shows SEM micrographs of fracture surfaces for polyester composites at $10 \mathrm{wt} \%$ of untreated or alkali treated DPF powder. It is clear that surface of untreated fiber is smooth, while the surface is more rough in the case of alkali treated fibers [31]. The figure indicates that the quality of filler and matrix bonding was significantly improved due to the treatment process in comparison with that of the composite containing untreated fiber, which showed poor adhesion between the fiber and the matrix consistent with results reported by Gharbi et al. [32].

For the morphology of the C7, a homogeneous surface and good adhesion of the DPF and sand were observed, as shown in Figure 4e. All the SEM micrographs are in accordance with the tensile and flexural properties of these composites.

\subsection{Thermogravimetric (TGA) and differential thermogravimetric (DTGA) analysis}

The thermal degradation of UP and UP based composites was studied. 1st derivative (DTG) and the thermograms of C0, C1, C4 and C7 are shown in Figures 5 and Figure 6, respectively. The summary of the important characteristic 
temperature obtained from the thermogram and DTG are listed in Table 3.

The table signifies that the treatment procedure induced a significant change in the residual mass of $\mathrm{C} 1$ and $\mathrm{C} 4$ from $16.68 \%$ to $9.14 \%$ due to the removal of hemicellulose during the alkali treatment. Moreover, the use of treated fiber improved significantly the thermal stability of the composites $[33,34]$. It was evident that alkali treated DPF exhibits better thermal stability over the untreated DPF fibers. The largest shift in the maximum degradation temperature was attributed to the sample containing treated DPF.

The incorporation of the sand particles resulted in pronounced improvement in thermal stability. This can be attributed to the much better thermal stability of inorganic particles (sand) and also their homogeneous distribution [35].

DTG curves in Figure 5 shows that the degradation is a two stage process the first peak corresponds mainly to the hemicelluloses and cellulose decomposition in the composites, the second peak which is the maximum peak of degradation slightly increased after introducing fillers to UP from 381.19 for UP to $382.81,384.15$ and $382.42^{\circ} \mathrm{C}$ for $\mathrm{C} 1, \mathrm{C} 4$ and $\mathrm{C} 7$, respectively. This shows that fillers enhanced the thermal stability of the composites at the higher temperatures [36].
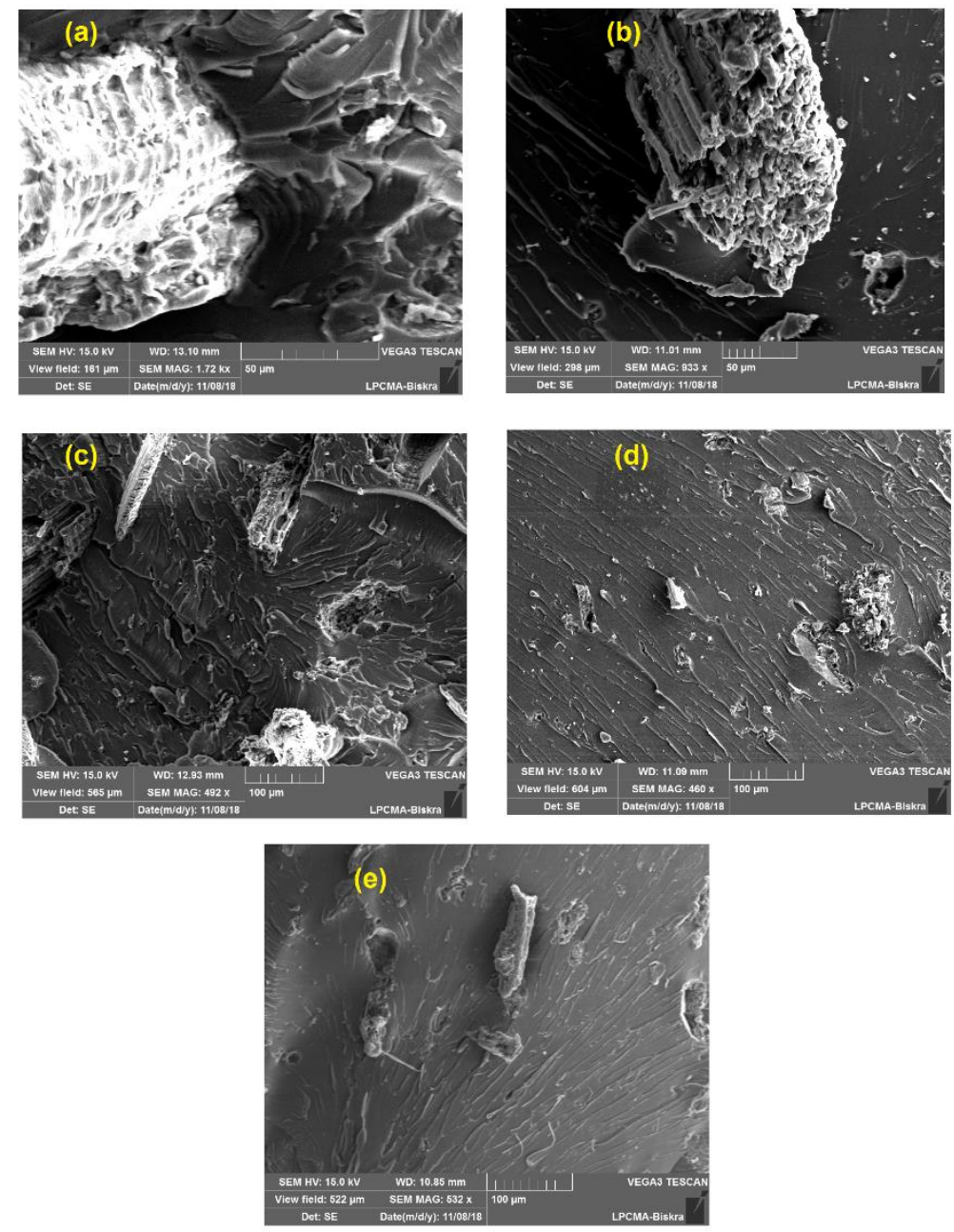

Figure 4. High magnification SEM photomicrographs of (a) DPF/Polyester (10/90) (C1), (b) TDPF/Polyester (10/90) (C4) and SEM photomicrographs of (c) DPF/Polyester (10/90) (C1), (d) TDPF/Polyester (10/90) (C4), (e) DS/DPF/Polyester (5/5/90) (C7)

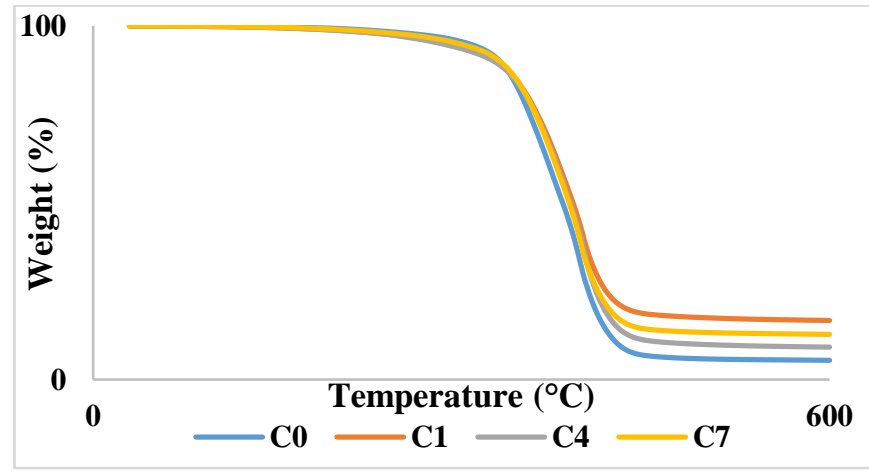

Figure 5. TGA plots of composites $\mathrm{C} 0, \mathrm{C} 1, \mathrm{C} 4$ and $\mathrm{C} 7$

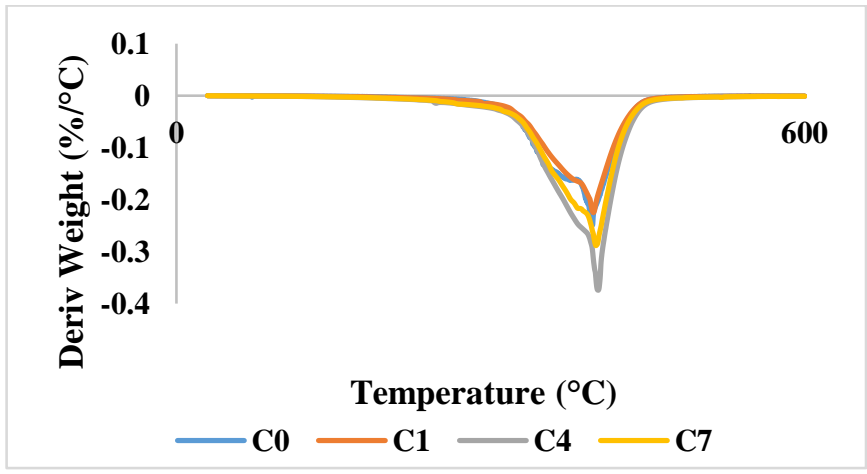

Figure 6. DTG plots of composites C0, C1, C4 and C7 
Table 3. Thermal properties of different UP based composites

\begin{tabular}{cccc}
\hline Samples (wt \%) & $\begin{array}{c}\text { Onset } \\
\text { temperature }\end{array}$ & $\begin{array}{c}\text { Tmax } \\
\left({ }^{\circ} \mathrm{C}\right)\end{array}$ & $\begin{array}{c}\text { Residue left } \\
(\%)\end{array}$ \\
\hline $\begin{array}{c}\text { UP/DPF/DS } \\
(\mathbf{1 0 0 / 0 / 0 )}\end{array}$ & 329 & 381.19 & 5.40 \\
\hline $\begin{array}{c}\text { UP/DPF/DS } \\
(\mathbf{9 0 / 1 0 / 0 )}\end{array}$ & 333 & 382.81 & 16.68 \\
\hline $\begin{array}{c}\text { UP/DPF/DS } \\
\text { (90/5/5) }\end{array}$ & 332 & 382.42 & 12.81 \\
\hline $\begin{array}{c}\text { UP/TDPF/DS } \\
(\mathbf{9 0 / 1 0 / 0 )}\end{array}$ & 331 & 384.15 & 9.14 \\
\hline
\end{tabular}

\subsection{Water absorption}

Water uptake under the immersion condition of composites versus time at different fillers loading is shown in Figure 7.
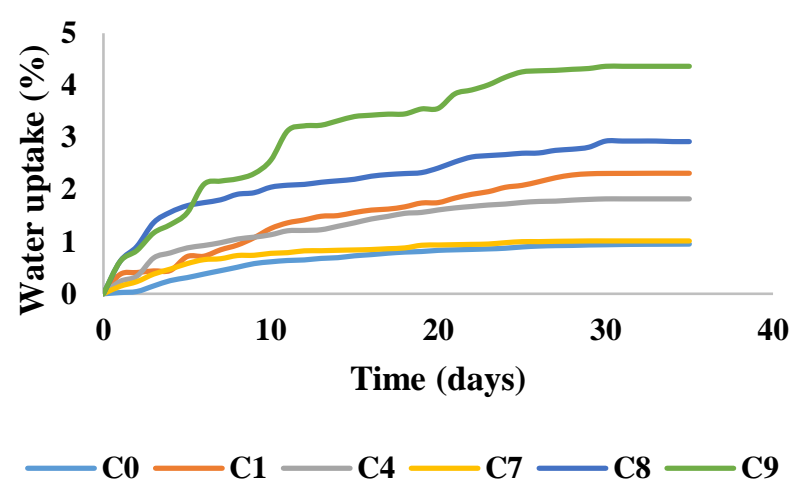

Figure 7. Water uptake under the immersion condition of composites versus time at different fillers loading

The decreased hydrophilic character of the filler after treatment with $\mathrm{NaOH}$ is contributing to the decrease in the water sensitivity of the composite [16]. In addition, unsaturated polyester reinforced with 5\% sand and 5\% DPF exhibited the lowest moisture absorption. This is due to the hydrophobic nature of sand and the decrease in the voids due to the well distribution of fillers in the matrix [7].

\section{CONCLUSION}

This article focuses on the effects of alkali treatment and dune sand addition on the mechanical, morphological, thermal and water absorption behaviors of DPF reinforced UP composites. Based on the findings and the discussion the following conclusions are summarized as below:

- The successful fabrications of unsaturated polyester based composites reinforced with date palm fiber and dune sand have been done.

- Physico-mechanical performance of the resulting composites being improved by alkali treatment.

- The experimental result reveals that the composite with $10 \mathrm{wt} \%$ fillers loading $(5 \mathrm{wt} \%$ date palm fiber and 5 wt $\%$ dune sand particles) shows better mechanical, morphological, thermal and water intake properties.

Generally, from all the above results, locally available and abundant resources can be valorized to fabricate new hybrid composites, which can be considered as the excellent candidates for various engineered and hi-tech applications.

\section{ACKNOWLEDGMENT}

The authors want to thank the staff of Laboratory of Entreprise Nationale des Plastiques \& Caoutchoucs, FIPEXPLAST, Chlef, Algeria, where the samples were prepared, and the (Centre de Recherche Christian Huygens, Lorient, France) for thermal analysis. This work is supported by Directorate General for Scientific Research and Technological Development (ALGERIA).

\section{REFERENCES}

[1] Lin, Y., Jiang, S., Hu, Y., Chen, G., Shi, X., Peng, X. (2018). Hybrids of aluminum hypophosphite and ammonium polyphosphate: Highly effective flame retardant system for unsaturated polyester resin. Polymer Composites, $39(5)$ : 1763-1770. https://doi.org/10.1002/pc.24128

[2] Dai, K., Song, L., Hu, Y. (2013). Study of the flame retardancy and thermal properties of unsaturated polyester resin via incorporation of a reactive cyclic phosphorus-containing monomer. High Performance Polymers, $25(8)$ : $138-946$. https://doi.org/10.1177/0954008313490767

[3] Hashemi, M.J., Jamshidi, M., Aghdam, J.H. (2018). Investigating fracture mechanics and flexural properties of unsaturated polyester polymer concrete (UP-PC). Construction and Building Materials, 163: 767-775. https://doi.org/10.1016/j.conbuildmat.2017.12.115

[4] Maou, S., Meghezzi, A., Nebbache, N., Meftah, Y. (2019). Mechanical, morphological, and thermal properties of poly (vinyl chloride)/low-density polyethylene composites filled with date palm leaf fiber. Journal of Vinyl and Additive Technology, 25(s2): E88-E93. https://doi.org/10.1002/vnl.21687

[5] Benzidane, R., Sereir, Z., Bennegadi, M.L., Doumalin, P., Poilâne, C., (2018). Morphology, static and fatigue behavior of a natural UD composite: The date palm petiole 'wood'. Composite Structures, 203: 110-123. https://doi.org/10.1016/j.compstruct.2018.06.122

[6] Mokhtari, A., Kriker, A., Guemmoula, Y., Boukrioua, A. (2015). Formulation and characterization of date palm fibers mortar by addition of crushed dune sand. Energy Procedia, 74: 344-350. https://doi.org/10.1016/j.egypro.2015.07.624

[7] Siala, A., Khay, S., Neji, J. (2017). Contribution of the addition of reclaimed asphalt pavement and dune sand on the hot-mix asphalt performances. Revue des Composites et des Matériaux Avancés, 27(1-2): 191-208. https://doi.org/10.3166/rcma.2017.00014

[8] Ismail, M.R., Ali, M.A.M., Afifi, M.S., El-Miligy, A.A. (1999). Studies on sand-unsaturated polyester composite materials. Polymer-Plastics Technology and Engineering, 38(2): $351-369$. https://doi.org/10.1080/03602559909351583

[9] Rajia, S., Rafia, A., Alam, M.Z., Rakibul, M.Q., Begum, M.H.A., Gafur, M.A. (2013). Preparation and characterization of sand reinforced polyester composites. International Journal of Engineering \& Technology, 
13(2): 111-118.

[10] Ahmad, T., Mamat, O., Ahmad, R. (2013). Studying the effect of adding silica sand nanoparticles epoxy based composites. Journal of Nanoparticles, 2013: 1-5. https://doi.org/10.1155/2013/603069

[11] Ahmad, T., Ahmad, R., Kamran, M., Wahjoedi, B., Shakoor, I., Hussain, F., Fahad Riaz, F., Jamil, Z., Isaac, S., Ashraf, Q. (2015). Effect of Thal silica sand nanoparticles and glass fiber reinforcements on epoxybased hybrid composite. Iranian Polymer Journal, 24: 2127. https://doi.org/10.1007/s13726-014-0296-x

[12] Ahmad, T., Raza, S.S., Aleem, E., Kamran, M., Manzoor, U., Makhdoom, A., Ahmad, R., Mukhtar, S. (2017). Improvement in mechanical and thermal properties of unsaturated polyester-based hybrid composites. Iranian Polymer Journal, 26: 305-311. https://doi.org/10.1007/s13726-017-0520-6

[13] Nimanpure, S., Hashmi, S.A.R., Kumar, R., Bhargaw, H.N., Kumar, R., Nair, P., Naik, A. (2019). Mechanical, electrical, and thermal analysis of sisal fibril/kenaf fiber hybrid polyester composites. Polymer Composites, 40(2): 664-676. https://doi.org/10.1002/pc.24706

[14] Birnin-Yauri, A., Ibrahim, N., Zainuddin, N., Abdan, K. Then, Y., Chieng, B. (2017). Effect of maleic anhydridemodified poly (lactic acid) on the properties of its hybrid fiber biocomposites. Polymers, 9(5): 165. https://doi.org/10.3390/polym9050165

[15] Boran, T.S., Pesman, E., Donmez, C.A. (2019). Effect of alkali treatment on composites made from recycled polyethylene and chestnut cupula. Polymer Composites, 40(11): 4442-4451. https://doi.org/10.1002/pc.25305

[16] Oushabi, A., Sair, S., Hassani, F.O., Abboud, Y., Tanane, O., El Bouari, A. (2017). The effect of alkali treatment on mechanical, morphological and thermal properties of date palm fibers (DPFs): Study of the interface of DPFPolyurethane composite. South African Journal of Chemical Engineering, 23(2017): 116-123. https://doi.org/10.1016/j.sajce.2017.04.005

[17] Negawo, T.A., Polat, Y., Buyuknalcaci, F.N., Kilic, A., Saba, N., Jawaid, M., Toler, A. (2019). Mechanical, morphological, structural and dynamic mechanical properties of alkali treated Ensete stem fibers reinforced unsaturated polyester. Composites Structures, 207(2019): 589-97.

https://doi.org/10.1016/j.compstruct.2018.09.043

[18] Alsaeed, T., Yousif, B.F., Ku, H. (2013). The potential of using date palm fibres as reinforcement for polymeric composites. Materials \& Design, 43: 177-184. https://doi.org/10.1016/j.matdes.2012.06.061

[19] Tomaszewska, J., Klapiszewski, L., Skórczewska, K., Szalaty, T.J., Jesionowski, T. (2017). Advanced organicinorganic hybrid fillers as functional additives for poly (vinyl chloride). Polimery Journal Online, 62(1): 19-26. http://doi.org/10.14314/polimery.2017.019

[20] Lin, Y., Jiang, S., Hu, Y., Chen, G., Shi, X., Peng, X. (2016). Hybrids of aluminum hypophosphite and ammonium polyphosphate: Highly effective flame retardant system for unsaturated polyester resin. Polymer Composites, $39(5)$ : $1763-1770$. http://doi.org/10.1002/pc.24128

[21] Shalwan, A., Yousif, B.F. (2014). Influence of date palm fibre and graphite filler on mechanical and wear characteristics of epoxy composites. Materials \& Design,
59:

http://doi.org/10.1016/j.matdes.2014.02.066

[22] Mirmehdi, S.M., Zeinaly, F., Dabbagh, F. (2014). Date palm wood flour as filler of linear low-density polyethylene. Composites Part B: Engineering, 56(2014) 137-141.

http://doi.org/10.1016/j.compositesb.2013.08.008

[23] Ikladious, N., Shukry, N., El-Kalyoubi, S., Asaad, J., Mansour, S., Tawfik, S., Abou-Zeid, R. (2017). Ecofriendly composites based on peanut shell powder / unsaturated polyester resin. Journal of Materials: Design and Applications, 1-10. http://doi.org/10.1177/1464420717722377

[24] Rahman, M.R., Hamdan, S., Hasan, M., Baini, R., Salleh, A.A. (2015). Physical, mechanical, and thermal properties of wood flour reinforced maleic anhydride grafted unsaturated polyester (UP) biocomposites. BioResources, 10(3): 4557-4568. http://doi.org/10.15376/biores.10.3.4557-4568

[25] Haameem, J.A.M., Abdul Majid, M.S., Afendi, M., Marzuki, H.F.A., Fahmi, I., Gibson, A.G. (2016). Mechanical properties of Napier grass fibre/polyester composites. Composite Structures, 136(2016): 1-10. http://doi.org/10.1016/j.compstruct.2015.09.051

[26] Shanmugasundaram, N., Rajendran, I., Ramkumar, T. (2018). Static, dynamic mechanical and thermal properties of untreated and alkali treated mulberry fiber reinforced polyester composites. Polymer Composites, 39(3): 1908-1919. https://doi.org/10.1002/pc.24890

[27] Chand, N., Dan, T.K., Verma, S., Rohatgi, P.K. (1987). Rice husk ash filled polyester resin composites. Journal of Materials Science Letters, 6(6): 733-735. http://doi.org/10.1007/bf01770943

[28] Patel, V.K., Dhanola, A. (2016). Influence of $\mathrm{CaCO}_{3}$, $\mathrm{Al}_{2} \mathrm{O}_{3}$, and $\mathrm{TiO}_{2}$ microfillers on physico-mechanical properties of Luffa cylindrica/polyester composites. Engineering Science and Technology, an International Journal, 19(2): 676-683. http://doi.org/10.1016/j.jestch.2015.10.005

[29] Turcsan, T., Meszaros, L. (2017). Mechanical performance of hybrid thermoset composites: Effects of matrix and reinforcement hybridization. Composites Science and Technology, 141: 32-39. http://doi.org/10.1016/j.compscitech.2017.01.005

[30] Nabinejad, O., Debnath, S., Ying, T.J., Liew, W.Y.H., Davies, I.J. (2017). Influence of alkali treatment and nanoclay content on the properties of rice husk filled polyester composites. Materials Science Forum, 882: 89100.

https://doi.org/10.4028/www.scientific.net/msf.882.89

[31] Nabinejad, O., Debnath, S., Rahman, M.E., Liew, W.Y.H., Davies, I.J. (2016). Mechanical and thermal characterization of polyester composite containing treated wood flour from Palm oil biomass. Polymer Composites, 39(4): https://doi.org/10.1002/pc.24052

1200-1211.

[32] Al-Kaabi, K., Al-Khanbashi, A., Hammami, A. (2005). Date palm fibers as polymeric matrix reinforcement: DPF/polyester composite properties. Polymer Composites, 26(5): 604-613. https://doi.org/10.1002/pc.20130

[33] Gharbi, A., Bel-Hassen, R., Boufi, S. (2014). Composite materials from unsaturated polyester resin and olive nuts residue: The effect of silane treatment. Industrial Crops 
[34] Arrakhiz, F.Z., Malha, M., Bouhfid, R., Benmoussa, K., Qaiss, A. (2013). Tensile, flexural and torsional properties of chemically treated alfa, coir and bagasse reinforced polypropylene. Composites Part B: Engineering, 47: http://doi.org/10.1016/j.compositesb.2012.10.046

[35] Arrakhiz, F.Z., Benmoussa, K., Bouhfid, R., Qaiss, A. (2013). Pine cone fiber/clay hybrid composite: Mechanical and thermal properties. Materials \& Design, 50:

376-381. http://doi.org/10.1016/j.matdes.2013.03.033

[36] El-Shekeil, Y.A., Sapuan, S.M., Jawaid, M., Al-Shuja'a, O.M. (2014). Influence of fiber content on mechanical, morphological and thermal properties of kenaf fibers reinforced poly(vinyl chloride)/thermoplastic polyurethane poly-blend composites. Materials \& Design, 58 :

$130-135$ http://doi:10.1016/j.matdes.2014.01.047

\section{NOMENCLATURE}

Unsaturated Polyester + untreated date palm fiber $(0 \mathrm{wt} \%)+$ dune sand $(0 \mathrm{wt} \%)$

Unsaturated Polyester + untreated date palm fiber $(10 \mathrm{wt} \%)+$ dune sand $(0 \mathrm{wt} \%)$

Unsaturated Polyester + untreated date palm fiber $(20 \mathrm{wt} \%)+$ dune sand $(0 \mathrm{wt} \%)$

Unsaturated Polyester + untreated date palm fiber $(30 \mathrm{wt} \%)+$ dune sand $(0 \mathrm{wt} \%)$

Unsaturated Polyester + treated date palm fiber $(10 \mathrm{wt} \%)+$ dune sand $(0 \mathrm{wt} \%)$

Unsaturated Polyester + treated date palm fiber $(20 \mathrm{wt} \%)+$ dune sand $(0 \mathrm{wt} \%)$

Unsaturated Polyester + treated date palm fiber $(30 \mathrm{wt} \%)+$ dune sand $(0 \mathrm{wt} \%)$

Unsaturated Polyester + untreated date palm fiber $(5 \mathrm{wt} \%)+$ dune sand $(5 \mathrm{wt} \%)$

Unsaturated Polyester + untreated date palm fiber $(10 \mathrm{wt} \%)+$ dune sand $(10 \mathrm{wt} \%)$

Unsaturated Polyester + untreated date palm fiber $(15 \mathrm{wt} \%)+$ dune sand (15 wt $\%)$ 